\title{
Review \\ The Potential of Visible and Far-Red to Near-Infrared Light in Glaucoma Neuroprotection
}

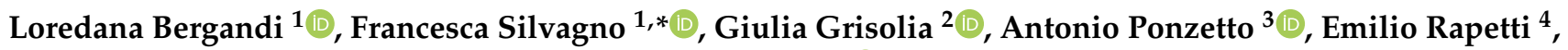 \\ Mariarosa Astori ${ }^{4}$, Antonio Vercesi ${ }^{5}$ and Umberto Lucia ${ }^{2}$ (D) \\ 1 Department of Oncology, University of Torino, Via Santena 5 Bis, 10126 Torino, Italy; \\ loredana.bergandi@unito.it \\ 2 Dipartimento Energia "Galileo Ferraris", Politecnico di Torino, Corso Duca Degli Abruzzi 24, \\ 10129 Torino, Italy; giulia.grisolia@polito.it (G.G.); umberto.lucia@polito.it (U.L.) \\ 3 Department of Medical Sciences, University of Torino, Corso A.M. Dogliotti 14, 10126 Torino, Italy; \\ antonio.ponzetto@unito.it \\ 4 Dipartimento di Oculistica, Azienda Ospedaliera Nazionale "SS. Antonio e Biagio e Cesare Arrigo", \\ Via Venezia 7, 15121 Alessandria, Italy; erapetti@ospedale.al.it (E.R.); mrastori@ospedale.al.it (M.A.) \\ 5 Studio Oculistico A. Vercesi, Via Massa Saluzzo 20, 15057 Tortona, Italy; info@studioavercesi.it \\ * Correspondence: francesca.silvagno@unito.it
}

Citation: Bergandi, L.; Silvagno, F.; Grisolia, G.; Ponzetto, A.; Rapetti, E.; Astori, M.; Vercesi, A.; Lucia, U. The Potential of Visible and Far-Red to Near-Infrared Light in Glaucoma Neuroprotection. Appl. Sci. 2021, 11, 5872. https://doi.org/10.3390/ app11135872

Academic Editor: Andrea Ballini

Received: 29 April 2021

Accepted: 22 June 2021

Published: 24 June 2021

Publisher's Note: MDPI stays neutral with regard to jurisdictional claims in published maps and institutional affiliations.

Copyright: (c) 2021 by the authors. Licensee MDPI, Basel, Switzerland. This article is an open access article distributed under the terms and conditions of the Creative Commons Attribution (CC BY) license (https:/ / creativecommons.org/licenses/by/ $4.0 /)$.

\begin{abstract}
Alternative treatment strategies are necessary to reduce the severity of glaucoma, a group of eye conditions that progressively damage the optic nerve and impair vision. The aim of this review is to gain insight into potentially exploitable molecular mechanisms to slow down the death of retinal ganglion cells (RGCs), a fundamental element in the pathophysiology of all forms of glaucoma, and to stimulate adult optic nerve repair. For this purpose, we focus our analysis on both visible and far-red to near-infrared light photobiomodulation (PBM) as phototherapeutic agents, which were recently proposed in RGCs, and on the nerve lamina region neural progenitor cell (ONLR-NPC) niche. Both are suggested as potential strategies in glaucoma neuroprotection. We discuss the impact of beneficial molecular effects of PBM on both mitochondrial derangement and the alteration of ion fluxes that are considered important causes of RGC damage, as well as on the stimulation of progenitor cells. We suggest these are the most promising approaches to prevent excessive neuronal cell loss. We describe the experimental evidence supporting the validity of PBM therapy which, despite being a safe, non-invasive, inexpensive, and easy to administer procedure, has not yet been fully explored in the clinical practice of glaucoma treatment.
\end{abstract}

Keywords: glaucoma; photobiomodulation (PBM); visible and far-red to near-infrared (FR/NIR) light therapy; low-level laser therapy (LLLT); retinal ganglion cells (RGC); mitochondrial dysfunction; nerve lamina region neural progenitor cell (ONLR-NPC) niche

\section{Introduction}

Glaucoma is a multifactorial chronic optic neuropathy with distinctive and usually irreversible, but preventable, visual field defects [1]. It is one of the leading causes of blindness worldwide, and it is characterized by optic nerve progressive changes with corresponding vision impairment [2]. The most important risk factor for glaucoma is the increase of intraocular pressure (IOP) [2]. Moreover, glaucoma is a major public health issue, as the population in Europe and most developed countries is ageing, a fact that will lead to an increasing burden of vision impairment over the next decades.

There are two major types of glaucoma (both open-angle and angle-closure on the basis of their anatomy and pathophysiology), and they share the same signs and symptoms: primary, or idiopathic glaucoma, and secondary glaucoma. Primary glaucoma results with no identifiable cause, whereas secondary glaucoma is characterized by an increased IOP that elicits optic nerve damage [3]. Only a few genes have been validated as risk factors for 
familial glaucoma [4], which is relatively rare. Primary angle-closure glaucoma shows a higher incidence of blindness, even though it is less common than open-angle glaucoma [3].

The mechanisms defining glaucomatous neurodegeneration are not fully understood [5]. To delay or halt retinal ganglion cell (RGCs) death, different strategies, including surgery and topically pharmacological agents, have been proposed; these prolong visual function, lower IOP, and succeed in reducing the rate of progression in defined subjects. Nevertheless, some glaucomatous patients do not benefit significantly from such treatments [6]. Therefore, various substances have been proposed as add-ons. These include antioxidants, nitric oxide synthase inhibitors and NO-donating agents, adenosine receptor antagonists, Rho-pathway inhibitors, PI3K/Akt activators, purinergic ligands, ATP-sensitive potassium channel (KATP) channel activators, glutamate antagonists, neurotrophic factors, dopamine and serotonin receptors ligands, cannabinoids, non-glucocorticoid steroidal compounds, histone deacetylase inhibitors [6,7], and the use of stem cells and gene therapy [8].

As improvements need to be made to reduce the severity of glaucoma, alternative treatment strategies are necessary. As such, the aim of this review is to gain insight into the potentially exploitable molecular mechanisms that can slow down RGCs death. A major mechanism for such death was suggested to be mitochondrial dysfunction and its related oxidative stress; indeed, mitochondrial potentiation and preservation is actively studied together, with the stimulation of progenitor cells being the most promising approach to prevent excessive RGC loss. This review will discuss the impact of mitochondrial derangement and the alteration of ion fluxes as being among the causes of RGC damage. Red light usage has been proposed as a non-invasive procedure to protect the death of RGCs in several diseases such as glaucoma, suggesting a mitochondrial effect of red/nearinfrared (R/NIR) phototherapy [9]. As such, we focused our attention on visible and farred/near-infrared light photobiomodulation (PBM) as phototherapeutic agents in RGCs, as well as on the nerve lamina region neural progenitor cell (ONLR-NPC) niche, as strategies in glaucoma neuroprotection. We will highlight the multiple beneficial molecular effects of visible and near red (NR) phototherapy.

Scopus and PubMed research databases were used to perform an electronic search from January 2011 to May 2021. The following filters were utilized in Scopus: human, classical article and review, engineering, medicine, biochemistry, genetics, and molecular biology. In PubMed, we used the following filters: humans, classical article, and review. Abstracts, case reports, and conference presentations were not included. The following medical subject headings $(\mathrm{MeSH})$, terms, or keywords were combined to identify the most relevant research studies: "glaucoma" AND "photobiomodulation" OR "visible light" OR "far-red light" OR "near-infrared light" OR "low energy photon irradiation" AND "mitochondria" OR "mitochondrial respiratory chain activity" OR "redox signaling" OR "oxidative stress" AND/OR "retinal ganglial cells" OR "nerve lamina region neural progenitor cell niche". Only English publications regarding human studies were selected, except for eight papers regarding in vitro and in vivo animal model studies that were recovered from the reference lists of some selected articles. An additional nine papers were considered, even though they were published before 2011. A total of 549 publications were selected through the research databases and carefully taken into consideration. Publications and duplicated articles that did not meet inclusion criteria were excluded; the remaining 66 articles were reviewed together with two patents retrieved using the following keywords: red light ocular treatments or visual system function (Figure 1). At present, the published studies have demonstrated the beneficial effects of photobiomodulation in in vitro human models, or in in vitro and in vivo animal models. This review aims to illustrate the most recent evidence supporting and encouraging the design of clinical trials that exploit photobiomodulation in the treatment of glaucoma. 


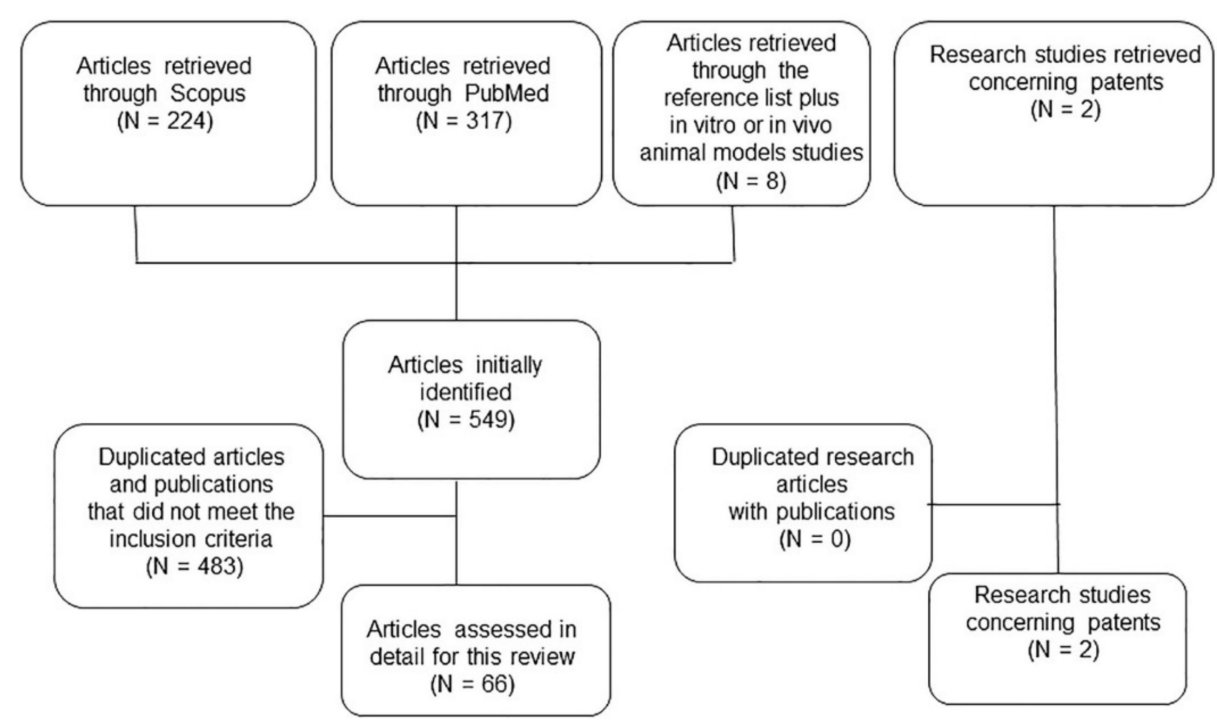

Figure 1. A comprehensive search strategy of scientific articles and clinical studies for this review paper.

\section{Photobiomodulation}

The utility of red light has been valued in the practice of medicine since ancient times, and it was "re-discovered" at the end of the 19th century by the Nobel Prize in Medicine and Physiology winner Niels Ryberg Finsen, who cured skin disorders with the use of red light [10]. The therapy consists of a series of brief illuminations with low energy photon irradiation in the visible (400-700 nm) and far-red (FR) to near-infrared (NIR) ranges of the electromagnetic spectrum $(700-1000 \mathrm{~nm})$; these methods are collectively termed photobiomodulation (PBM) and are carried out by different devices, including a laser, a light emitting diode (LED), or a broadband light. Notably, LEDs generate negligible amounts of heat, thus reducing the risk of thermal injury and tissue damage, which instead occurs during the use of lasers [11].

The source and the pulse structure of the light, as well as the wavelength and the density of the energy and the duration of the laser application are important parameters for the effectiveness of PBM on the target tissue [12]. Regarding the type of wave, whether continuous or pulsed, there are still conflicting opinions as to which is the best and which factors should determine the pulse parameters [13].

High tissue penetration is achievable by the long wavelengths. To accelerate wound healing, reduce neurologic pain, and potentiate healing after peripheral nerve injury, ischemic stroke and heart attack, PBM therapy is currently applied [14]. Thus, applications of PBM offer a promising innovative and non-invasive therapeutic approach to a host of challenging sight-threatening retinal conditions, including methanol-induced retinal damage, retinopathy of prematurity, diabetic retinopathy, Leber's hereditary optic neuropathy, age-related macular degeneration, amblyopia, and possibly others [10]. Indeed recent studies have demonstrated that diseased tissues, including the retina, are penetrated by FR/NIR photons, which are most effective at inducing beneficial effects in vivo in cells without apparent specialized photopigments [15].

\section{Pathophysiology of Glaucoma: Increased IOP, Mitochondrial Dysfunction, and Altered Ion Fluxes}

The following parameters are risk factors in relation to glaucoma: Older age and frailty, African descent, familiarity with glaucoma, diabetes [16], use of systemic or topical corticosteroids [17], myopia, ocular diseases, reduced central corneal thickness [18], trauma and surgery [19], smoking, ischemic event, hypertension, and vasospasm [20]. These all contribute to an increase in the eye pressure, which is the most important risk factor for glaucoma [2]. Eye pressure is thought to cause direct damage to neurons and to the optic 
nerve [21]. Indeed, the disease is characterized by the progressive degeneration of both RGCs, the projection neurons of the eyeand axons.

The balance between the secretion of aqueous humor by the ciliary body and its drainage through two independent pathways- the trabecular meshwork (TM) and uveoscleral outflow pathway-is very important, as progressive resistance to outflow results in a gradual increase in IOP [17], which triggers glaucomatous pathogenesis [22]. An increased resistance to aqueous outflow through the trabecular meshwork is reported in patients suffering from open-angle glaucoma. In contrast, access to the drainage pathways is anatomically obstructed in patients with angle-closure glaucoma [17]. Notably, similarly to endothelial-like cells, TM cells also lie in the collagen meshwork beams, and they are significantly decreased; moreover, they show both mitochondrial permeability transition pore alteration and mitochondrial release of calcium, both of which are increased in glaucoma patients compared to healthy subjects [22]. The dysfunction of calcium regulation by these cells may cause the failure to control IOP by TM tissue.

Due to its sensitivity to high IOP, progressive and chronic stress is conveyed or transduced through the optic nerve head to the unmyelinated RGC axon segment. This is executed in complex ways that include mechanical, inflammatory, and bioenergetic components [23]. However, in individuals with normal IOP and in patients whose IOP is effectively controlled by medical treatment, but who continue to suffer progressive neuron loss and visual field deterioration, glaucomatous RGCs and axon loss occur [24]. This suggests that other not fully understood mechanisms beyond pressure-mediated damage are involved in neurodegeneration [5,21]. Indeed, there is the possibility that pathophysiological stress, such as that induced by elevated IOP, triggers secondary immune or autoimmune responses, leading to RGC and axon damage after the initial insult is gone. In fact, evidence suggests that the transient elevation of IOP is sufficient to induce autoreactive $\mathrm{T}$ lymphocytes and T-cell infiltration into the retina in mice; the importance of this mechanism was demonstrated by the lack of T-cell autoreactivity in germ-free mice, even after long-term experimentally induced IOP elevation. This T-cell infiltration leads to a prolonged phase of RGCs degeneration that also persists after IOP returns to a normal level [21], suggesting an autoimmune component in glaucoma.

Importantly, mitochondrial failure has been implicated in the aetiology of retinitis pigmentosa and in retinal degeneration in glaucoma in a way that is similar to neurodegenerative diseases such as Alzheimer's and Parkinson's [25]. In some illnesses, a specific loss of RGCs is a common feature. Indeed similarities exist between glaucoma and mitochondrial optic neuropathies, such as Leber's hereditary optic neuropathy and autosomal dominant optic atrophy [26]. Barron et al. found a high density of voltage-gated $\mathrm{Na}^{+}$ channels and increased numbers of mitochondria in the pre-laminar optic nerve, which reflects the higher energy requirements for electrical conduction in unmyelinated axons in the pre-laminar and laminar optic nerve [27]. Due to their peculiar structural and energetic constraints, RGCs appear to be acutely susceptible to mitochondrial dysfunction; for this reason, the death of RGCs is the hallmark of glaucomatous optic neuropathy.

Moreover, as mitochondrial function is also deemed to decline in neurons with aging, mitochondrial dysfunction, as either a cause or consequence of injury, renders RGCs sensitive to degeneration, which may be related to the increasing incidence of glaucoma with advancing age [28].

A further alteration observed in primary glaucoma-especially in the intermittent stage of angle closure glaucoma-is the change in quality and quantity of mitochondria in the iris tissue cells; for example, the disappearance of the mitochondrial crest and vacuole changes were reported. These morphological alterations are accompanied by an increase in intracellular reactive oxygen species (ROS) generation, higher intracellular calcium levels, and lower anti-oxidant expression in glaucomatous lamina cribrosa (LC) cells compared to that in normal cells; the alterations are also related to the pathogenesis of glaucoma to some extent [22]. Similar to the neurons of the central nervous system, RGCs depend on ATP generated by mitochondria in order to preserve ionic gradients and survive [8], and 
any mitochondrial dysfunction will lead to cell damage [29]. The inhibition of enzyme processes, which affect oxidative phosphorylation [29], leads to reduced ATP formation and increased oxidative stress, and finally results in cell death [8].

A decreased energy availability can have a strong impact on the maintenance of ion fluxes which are responsible for neuronal activity. As a consequence, or in addition, defects in ion channel activity can contribute to neuronal death. In glaucoma and other retinal disorders, the expression and function of $\mathrm{K}^{+}$channels in Müller glia (critical for preserving the proper physiology of RGCs) are altered [30]. The results of a recent study suggest that both $\mathrm{K}^{+}$and $\mathrm{Na}^{+}$homeostasis may be chronically changed in glaucoma [31]. In fact, it was demonstrated in vitro that, in Müller glia, the elevated pressure alters cation homeostasis and cation channel flux. The prolonged disruption of these gradients could contribute to the reported alterations in the electrophysiological properties of RGCs in glaucomatous retina $[32,33]$. Transient receptor potential vanilloid 4 (TRPV4) cation channels are important $\mathrm{Ca}^{2+}$ entry pathways that are sensitive to shear stress. Their activation triggers localized calcium influx and lowers IOP in rats and mice [34]. An interesting recent work carried out on human TM cells showed that the mechanism of action of TRPV4 channels is mediated by calcium-induced eNOS (endothelial NO synthase) activation and NO (nitric oxide) production [35]. The consequent vasodilation can explain the decrease in IOP observed in animals. The study demonstrated that TM cells are insensitive to shear stress, as the activity of TRPV4 channels is impaired in glaucoma. Glaucoma-associated functional impairment of TRPV4 channels may contribute to IOP elevation over time, leading to glaucomatous neurodegeneration. Upon calcium entry, its physiological levels are balanced by energy-dependent calcium efflux mechanisms; therefore, mitochondrial activity must be strictly coupled to the activity of ion channels. If this balancing mechanism should fail, the excessive calcium influx could be detrimental to TM physiology and could justify the observations obtained in both human and animal models, which link TRPV4 activity with TRPV4-dependent cytoskeletal remodeling, TM stiffness, and outflow, leading to elevated IOP [36]. Calcium mishandling damages mitochondria and unlashes mitochondrial apoptotic pathways involved in caspase activation. Additionally, the caspase-dependent apoptotic pathway induced by a prolonged inflammatory condition can lead to RGC death. Indeed, apoptotic caspases $-3,-8$, and -9 are cleaved in RGC after a period of elevated IOP, and inflammatory caspases $-1,-4$, and -12 are also upregulated [37].

\section{Visible and Far-Red to Near-Infrared Photobiomodulation in RGCs in Mitochondrial Protection and Energy Metabolism}

The major goal of basic and translational research is to enhance the viability of RGCs in order to maintain their function [29]. Various strategies targeting mitochondrial protection provide a promising way to delay the onset of glaucoma or protect RGCs against glaucomatous damage, as mitochondria play an important role in the pathogenesis of primary open-angle glaucoma [8]. Specifically, experimental studies have shown that the light of different wavelengths can directly affect oxidative phosphorylation in a wavelengthspecific manner when it is absorbed by mitochondrial chromophores [29]. Indeed, some studies have shown that RGCs possess a high number of mitochondria and are sensitive to the exposure of visual red light $(680-900 \mathrm{~nm})$, which has been reported to be absorbed by cytochrome-c-oxidase (COX), a key enzymatic complex for cell bioenergetics, especially nerve cells in the retina and brain. $\mathrm{COX}$ contains four redox metal centers, $\mathrm{Cu}_{\mathrm{A}}, \mathrm{Cu}_{\mathrm{B}}, \mathrm{Hem}$ $\mathrm{a}$, and Hem $\mathrm{a}_{3}$, where electrons are transferred sequentially; different light wavelengths determine peaks of absorption for the complex: $620 \mathrm{~nm}$ (range 613.5-623.5 nm), $825 \mathrm{~nm}$ (range 812.5-846 nm), 760 nm (range 750.7-772.3 nm), and $680 \mathrm{~nm}$ (range 667.5-683.7 nm), which correspond to $\mathrm{Cu}_{\mathrm{A}}$ reduced, $\mathrm{Cu}_{\mathrm{A}}$ oxidized, $\mathrm{Cu}_{\mathrm{B}}$ reduced, and $\mathrm{Cu}_{\mathrm{B}}$ oxidized, respectively. In neural tissue, COX is the most abundant metalloprotein complex, and its exposure to light at $670 \mathrm{~nm}$ and $830 \mathrm{~nm}$ correlates highly with its peaks in catalytic activity, as well as with ATP content in animal models in vitro [38].

ROS and NO, which are among the secondary mediators of PBM, are able to activate signaling pathways and transcription factors [39], demonstrating that redox equilibrium 
is important in the physiology of cells; it is also central in pathological events due to the ability of ROS to activate or inactivate various proteins, receptors, ions, and other signaling molecules. Notably, many cellular signaling pathways are perturbed, leading to cellular dysfunction and, subsequently, the development of various pathologies, among which are eye diseases; this occurs when the redox equilibrium is disturbed due to the excessive accumulation or depletion of ROS. In this context, PBM may also function by increasing the bioavailability of $\mathrm{NO}$ by prompting its release from intracellular stores, such as heme-containing proteins under normoxic conditions. Since NO functions as an inhibitor of mitochondrial respiration, its dissociation from cytochrome $C$ oxidase would restore mitochondria's oxygen consumption which, in turn, should increase energy production and boost cellular metabolism [10]. Thus, it is currently accepted that red light enhances the mitochondrial function, thereby improving mitochondrial energy metabolism and the consequent increase in mitochondrial membrane potential $(\Delta \Psi)$ and proton gradient $(\Delta \mathrm{pH})$. Therefore, red light exerts a cytoprotective function by preventing apoptotic cell death, as demonstrated in animal models in vivo $[14,26]$ and, consequently, it can reduce the damage caused by a variety of conditions studied in animal models in vivo [9,40-42].

The successful attenuation of histopathological changes in animal retina in situ $[34,39,40,42-44]$ is supported by the clinical use of far-red to near-infrared (FR/NIR) therapy to enhance mitochondrial function. Animal studies have specifically shown that optimum treatment conditions using red light for a short period of time $\left(16.5\right.$ watts $/ \mathrm{m}^{2}$, 3000 lux, $625-635 \mathrm{~nm}$ ) can attenuate an insult of raised IOP to the rat retina and retinal dysfunctions [9], with no detectable harmful effects on the lens, cornea, and retina, thus dispelling previous doubts about its therapeutic safety $[45,46]$.

The beneficial effects of PBM on the neural and vascular elements of the retina have also been supported by a study from Lu et al., which showed that a $670 \mathrm{~nm}$ light $9 \mathrm{~J} / \mathrm{cm}^{2}$ used once daily over 5 days reduces the Müller cell-mediated retinal inflammation of an animal model both in vivo and in vitro [47,48], offering a potential cellular mechanism for $670 \mathrm{~nm}$ light therapy in regulating inflammation associated with retinal degenerations. In fact, both the expression of COX5a and the mitochondrial membrane potential $(\Delta \Psi \mathrm{m})$ were increased, and the microglia/macrophage recruitment into the outer retina was reduced. This is of importance, as non-neuronal components of the retina and glial-derived Müller cells, are the supporting cells of the retina that play a key role in maintaining retinal homeostasis and responding to retinal stress through the release of chemokines to recruit microglia and macrophages into the damaged retina, where gliosis is a feature of eye disease progression. This highlights the value of low-level laser therapy (LLLT) as a novel paradigm to treat visual failure, and it supports the opinion that neuronal energy metabolism could constitute a major target for neurotherapeutics of both the brain and the eye [15].

Interestingly, calcium channels are modulated by red light, as demonstrated by recent works. In fact, a study reported that an LED light at $630 \mathrm{~nm}(26$ and $39 \mathrm{~J} / \mathrm{cm}, 4$ times every $3 \mathrm{~h}$ within $12 \mathrm{~h}$ ) could promote TRPV4 expression in human synovial fibroblasts [49]. These observations suggest the utility of further studies investigating the effects of PBM on TRPV4 in glaucoma.

A schematic representation of putative protective effects of PBM on cell metabolism is shown in Figure 2. In glaucoma, mitochondrial dysfunction is a component of a complex multifaceted disease, together with other signs of derangement such as increased IOP and defective ion fluxes. Restoring mitochondrial activity could affect RGC survival differently, depending on the severity of the other pathological components; however, the potentiated energy production should at least be a beneficial, if not a resolutive, approach. Based on these considerations, photobiomodulation could stimulate several defective components and could have a stronger beneficial effect than the pharmacological singletarget treatments. 

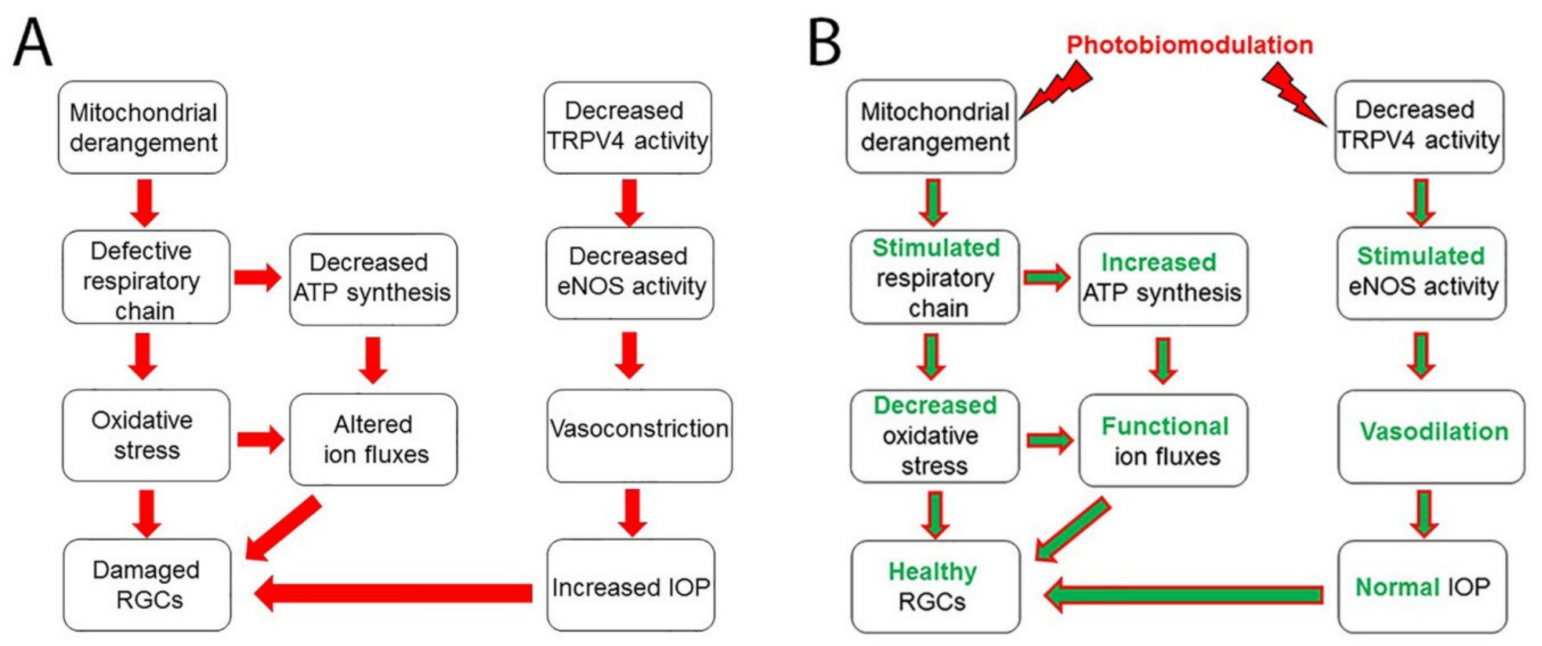

Figure 2. A schematic representation of putative protective effects on cell metabolism in the presence of PBM (Panel B) compared to those in the absence of PBM (Panel A). Abbreviation: transient receptor potential vanilloid 4 (TRPV4) cation channels.

\section{Visible and Far-Red to Near-Infrared Photobiomodulation in Neuronal Differentiation}

Many studies have found that mesenchymal stem cells (MSCs) can be used in the treatment of neurological diseases, including Alzheimer's, spinal cord injury, and stroke; this is because the differentiation of MSCs could be multi-directional and it is regulated in vivo by many factors [50]. However, uncontrolled proliferation and even tumor formation are due to a lack of guidance and regulation; this remains a major safety concern in the use of stem cells for therapeutic intervention. Additionally, in glaucoma, the regenerative potentialities of MSC could be vital in the substitution of damaged RGCs, but their differentiation should be tightly controlled.

In the neurological field, photobiomodulation therapy (PBMT) acts on neural cells as a complementary treatment of spinal cord trauma, traumatic brain degeneration/injury, and in the process of peripheral nerve regeneration [38]. Indeed, there is a relationship between the improvement in trophic conditions and a reduction in inflammatory processes; this is closely related to more efficient nervous regeneration, ATP production, enhanced secretion of neural factors, increased vascular network, and collagen synthesis, and it facilitates neural differentiation and regeneration $[38,51]$ due to the photochemical and photobiological effects of PBM at the cellular level.

The potential role of PBM in stimulating cell differentiation has been described in various in vitro human stem cell models. Indeed, a $810 \mathrm{~nm}$ wavelength was used to stimulate dental pulp stem cells [52], and red $(660 \mathrm{~nm})$ and near-infrared $(810 \mathrm{~nm})$ red lights were shown to be more effective than blue and green $(415 \mathrm{~nm}$ and $540 \mathrm{~nm})$ in inducing a differentiation of human adipose-derived stem cells (hASC) into osteoblasts when they were cultured in an osteogenic medium. In fact, after green/blue stimulation, intracellular calcium and ATP production were lower compared to after the red light, and they were associated with higher level of ROS [53]. Recently, irradiation with a laser light at $808-\mathrm{nm}$, delivering energy densities from 0 to $10 \mathrm{~J} / \mathrm{cm}^{2}$, has been demonstrated to induce early stage neuronal differentiation rather than glial differentiation in human umbilical cord mesenchymal stem cells [54].

Additionally, neuromodulation is achievable by photostimulation; indeed, when the principal glial cells of peripheral neural system, human Schwann cells, were treated with a diode laser at $810 \mathrm{~nm}$ and $50 \mathrm{~mW}\left(1 \mathrm{~J} / \mathrm{cm}^{2}\right.$ and $\left.4 \mathrm{~J} / \mathrm{cm}^{2}\right)$ for three days, cell proliferation and nerve growth factor (NGF) gene expression were stimulated on day 20 [51].

However, emerging evidence also suggests a plausible role for blue light in neural stem cells (NSCs), the quiescent adult cells residing in specific regions of the mammalian brain; 
these, in fact, constitutively express blue and red light-sensitive photoreceptors. Indeed, Wang et al. showed a 4.3-fold increase in proliferation and 2.7-fold increase in differentiation toward astrocyte phenotype of the abovementioned NSCs upon low-power blue monochromatic light exposure $\left(455 \mathrm{~nm}, 300 \mu \mathrm{W} / \mathrm{cm}^{2}\right)$; the melanopsin (Opn4)/transient receptor potential channel 6 (TRPC6) non-visual opsin might serve as a key photoreceptor response to blue light irradiation. This also suggests that the blue light-triggered system of NSCs could enable nongenetic and non-invasive neuromodulation, with therapeutic potential for central nervous system diseases [55].

These findings are of relevance, as Bernstein et al. recently demonstrated that the optic nerve lamina region (ONLR) contains a neural progenitor cell (NPC) niche, which may have a role in both postnatal optic nerve development and in adult optic nerve support and repair [56]. Unmyelinated retinal ganglion cell axons originating in the retina pass through the ONLR, the most anterior portion of the optic nerve, before myelination occurs in the more distal portion of the optic nerve. However, the precise sites of postnatal RGC axonal growth and the mechanism by which myelination occurs at sites of newly formed axonal membrane late in postnatal growth are still obscure [56]. It is well known that ONLR has a number of unusual characteristics: it inhibits intraocular myelination, enables postnatal optic nerve myelination of growing axons, modulates the fluid pressure differences between eye and brain, and is the primary lesion site in age-related open-angle glaucoma. It remains to be investigated whether PBM therapy with red light can effectively stimulate NPC and at least in part regenerate the tissue damaged by glaucoma.

\section{Current and New Approaches in Glaucoma Treatment Modalities}

The most common treatment for glaucoma is prescription eye drops. In addition to the well-known hypotensive drugs, modern devices for instilling local and systemic drugs are also used to reduce intraocular pressure [57]. However, poor compliance and fluctuating adherence of patients to the therapy are the main disadvantages of eye drop treatment.

Concerning laser therapy, diode laser trabeculoplasty (DLT) uses lower energy spots than SLT (selective laser trabeculoplasty) and ALT (argon laser trabeculoplasty) [58] for the same performance, and micropulse diode laser trabeculoplasty (MDLT) [59] emits microspots to limit laser heat-induced damage to adjacent structures.

Regarding surgery, even if the traditional trabeculectomy technique remains the gold standard of treatment, the latest research has been focused on improving its risk/benefit ratio for minimally invasive glaucoma surgery (MIGS) [60]. This method could be used in eyes with mild or medium-mild grade glaucoma, or in patients who do not tolerate drops or do not respond to laser treatment, as it is a safe and efficient technique to lower IOP compared to standard surgery; however, its costs are elevated.

In light of the growing costs of these drugs/devices and their impact on the economy of various countries, PBM therapy may offer a novel, safe, and effective therapy choice for improving the quality of life of patients, including the elderly and the poor; it may also have a major impact on medical practice and public finances, and cost a fraction of many current approaches [61]. However, the drawbacks of this technology are due to the lack of consistency in the choice of parameters such as the wavelength, the amount of energy consumed, the surface of contact, and the duration of treatment. Most researchers believe that, in relation to many diseases, the efficiency of PBM is positive [62]. Finally, the search for qualitative and quantitative standards should be undertaken in the clinical setting to achieve original protocols to treat diseases with photobiomodulation.

\section{Existing Patents for Ocular Treatments Using Laser Red Light}

Currently, it is well known that, in vivo, LLLT leads to a significant improvement in visual acuity in adolescent and adult patients with amblyopia caused by ametropia or strabismus. This procedure is most effective when an area of the macula is irradiated through the conjunctiva from $1 \mathrm{~cm}$ distance for $30 \mathrm{~s}$ with a laser light $(780 \mathrm{~nm}, 292 \mathrm{~Hz}, 1: 1$ duty cycle; $7.5 \mathrm{~mW}$; spot area $3 \mathrm{~mm}$, repeated on average 3.5 times) [60]. Moreover, two patents 
were filed concerning LLLT. Specifically, the one by LumiThera describes a device and a method for non-invasive multi-wavelength photobiomodulation for ocular treatments [63] of symptoms of acute or chronic ocular syndromes, such as diabetic retinopathy, retinitis pigmentosa, glaucoma, age-related macular degeneration, central serous retinopathy, non-arteritic anterior ischemic optic neuropathy, and Leber's hereditary optic neuropathy; treatment is also provided to the eyelids, wrinkles, cheratitis, viral and bacterial infections, and many more areas. Irradiance with multiple wavelengths is provided by multiple laser sources ( $25 \mathrm{~nm}$ to $900 \mathrm{~nm}$ pulsed at frequencies from 1 to $100 \mathrm{Herz}$, or from $100 \mathrm{~Hz}$ to $100 \mathrm{kHz}$ for 1 millisecond up to $150 \mathrm{~s}$ ). Furthermore, a method for treating visual system diseases is disclosed in this first patent. In the other one patent, which was sponsored by the Department of Defense Advanced Research Project Agency (USA), the aim was to restore vision after methanol toxicity. It is based on the use of LEDs developed by NASA and consists of (a) exposing a component of a patient's visual system to light treatment (wavelength between $630-1000 \mathrm{~nm}, 10-90 \mathrm{~mW} / \mathrm{cm}$ for 1-3 min), and (b) observing the restoration of visual system function [64].

\section{The Future of Clinical Trials for the Treatment of Glaucoma}

Generally, glaucoma is a disease that progresses slowly; hence, there have been concerns regarding the feasibility of conducting clinical trials to evaluate the efficacy of new treatments for slowing or preventing vision loss [65]. It is generally believed that such trials would require very large sample sizes or long follow-ups. Nevertheless, clinical trials for glaucoma neuroprotection are not impossible. When treatment efficacy is evaluated by (1) difference in incidence of pointwise event-based progression, and (2) difference in rate of visual field mean deviation (MD) change between groups using linear mixed models (LMMs) versus conventional event-based survival analysis, the feasibility of future glaucoma clinical trials can be improved substantially [66].

The studies described in this review highlight the relevance of some intracellular pathways which could be novel therapeutic targets, with the intent of lowering IOP on one side and stimulating tissue regeneration on the other side. The potentiation of mitochondrial activity associated with ion flux control could be proposed as a metabolic approach that is worthy of being pursued, and the therapy with red light could be used with this aim. In addition, a thermophysical approach to glaucoma has recently been developed by improving the comprehension of the biophysical bases of the light-receptor mechanism in order to design new possible devices for therapies [67].

If PBM usefulness could be established through large clinical trials, it would offer a non-invasive and inexpensive approach that could easily be delivered by medical providers, or even by patients themselves, for the prevention or slowing down of the progress of retinal pathologies [10], including glaucoma.

\section{Conclusions}

As justly noted by Dr. Michael R. Hamblin, "after decades confined to the scientific wasteland, PBM may be finally emerging into the light of day (pun intended)" [68]. Indeed, as various prophylactic and therapeutic strategies targeting mitochondrial protection might provide a promising way to delay the onset of glaucoma, PBM could be useful in ameliorating mitochondrial function and/or stimulating progenitor cells to slow down RGC death in glaucoma. Moreover, PBM has been documented to have minimal risk, to be non-invasive, inexpensive, and easy to administer.

Author Contributions: Conceptualization, F.S., A.P., M.A. and U.L.; methodology, L.B.; validation, L.B., G.G., E.R. and A.V.; formal analysis, L.B., F.S., A.P., E.R. and M.A.; investigation, F.S., G.G. and A.V.; resources, U.L.; data curation, L.B., M.A. and A.P.; writing-original draft preparation, L.B., F.S., A.P., M.A. and U.L.; writing—review and editing, L.B., F.S., A.P., M.A. and U.L.; visualization, L.B. and F.S.; supervision, U.L.; project administration, L.B.; funding acquisition, U.L. All authors have read and agreed to the published version of the manuscript. 
Funding: This research was funded by LINKS Foundation (Torino, Italy), LIFTT (Torino, Italy), Fondazione Compagnia di San Paolo (Torino, Italy), and Politecnico di Torino (Italy) in support of the PoCInstrument project "Dispositivo e metodo per la riabilitazione visiva".

Institutional Review Board Statement: Not applicable.

Informed Consent Statement: Not applicable.

Acknowledgments: Three of the authors (L.B., G.G. and U.L.) must thank LINKS Foundation (Torino, Italy), LIFTT (Torino, Italy), Fondazione Compagnia di San Paolo (Torino, Italy), and Politecnico di Torino (Italy) for their support for the PoCInstrument project "Dispositivo e metodo per la riabilitazione visiva".

Conflicts of Interest: The authors declare no conflict of interest.

\section{References}

1. Kreft, D.; Doblhammer, G.; Guthoff, R.F.; Frech, S. Prevalence, Incidence, and Risk Factors of Primary Open-Angle Glaucoma-A Cohort Study Based on Longitudinal Data from a German Public Health Insurance. BMC Public Health 2019, 19. [CrossRef] [PubMed]

2. Jayanetti, V.; Sandhu, S.; Lusthaus, J.A. The Latest Drugs in Development That Reduce Intraocular Pressure in Ocular Hypertension and Glaucoma. J. Exp. Pharmacol. 2020, 12, 539-548. [CrossRef]

3. Allison, K.; Patel, D.; Alabi, O. Epidemiology of Glaucoma: The Past, Present, and Predictions for the Future. Cureus 2020, 12, e11686. [CrossRef] [PubMed]

4. Chang, E.E.; Goldberg, J.L. Glaucoma 2.0: Neuroprotection, Neuroregeneration, Neuroenhancement. Ophthalmology 2012, 119, 979-986. [CrossRef] [PubMed]

5. McKinnon, S.J.; Goldberg, L.D.; Peeples, P.; Walt, J.G.; Bramley, T.J. Current Management of Glaucoma and the Need for Complete Therapy. Am. J. Manag. Care 2008, 14, S20-S27. [PubMed]

6. Gandolfi, S.; Marchini, G.; Caporossi, A.; Scuderi, G.; Tomasso, L.; Brunoro, A. Cytidine 5'-Diphosphocholine (Citicoline): Evidence for a Neuroprotective Role in Glaucoma. Nutrients 2020, 12, 793. [CrossRef]

7. Gauthier, A.C.; Liu, J. Neurodegeneration and Neuroprotection in Glaucoma. Yale J. Biol. Med. 2016, 89, 73-79. [PubMed]

8. Osborne, N.N.; del Olmo-Aguado, S. Maintenance of Retinal Ganglion Cell Mitochondrial Functions as a Neuroprotective Strategy in Glaucoma. Curr. Opin. Pharmacol. 2013, 13, 16-22. [CrossRef]

9. Del Olmo-Aguado, S.; Núñez-Álvarez, C.; Osborne, N.N. Red Light of the Visual Spectrum Attenuates Cell Death in Culture and Retinal Ganglion Cell Death in Situ. Acta Ophthalmol. 2016, 94, e481-e491. [CrossRef]

10. Geneva, I.I. Photobiomodulation for the Treatment of Retinal Diseases: A Review. Int. J. Ophthalmol. 2016, 9, 145-152. [CrossRef]

11. Okuyama, S.; Nagaya, T.; Ogata, F.; Maruoka, Y.; Sato, K.; Nakamura, Y.; Choyke, P.L.; Kobayashi, H. Avoiding Thermal Injury during Near-Infrared Photoimmunotherapy (NIR-PIT): The Importance of NIR Light Power Density. Oncotarget 2017, 8 , 113194-113201. [CrossRef]

12. Dompe, C.; Moncrieff, L.; Matys, J.; Grzech-Leśniak, K.; Kocherova, I.; Bryja, A.; Bruska, M.; Dominiak, M.; Mozdziak, P.; Skiba, T.H.I.; et al. Photobiomodulation-Underlying Mechanism and Clinical Applications. J. Clin. Med. 2020, 9, 1724. [CrossRef]

13. Hashmi, J.T.; Huang, Y.-Y.; Osmani, B.Z.; Sharma, S.K.; Naeser, M.A.; Hamblin, M.R. Role of Low-Level Laser Therapy in Neurorehabilitation. PMER 2010, 2, S292-S305. [CrossRef]

14. Eells, J.T.; Gopalakrishnan, S.; Valter, K. Near-Infrared Photobiomodulation in Retinal Injury and Disease. Adv. Exp. Med. Biol. 2016, 854, 437-441. [CrossRef]

15. Rojas, J.C.; Gonzalez-Lima, F. Low-Level Light Therapy of the Eye and Brain. Eye Brain 2011, 3, 49-67. [CrossRef]

16. Sayin, N.; Kara, N.; Pekel, G. Ocular Complications of Diabetes Mellitus. World J. Diabetes 2015, 6, 92-108. [CrossRef]

17. Weinreb, R.N.; Aung, T.; Medeiros, F.A. The Pathophysiology and Treatment of Glaucoma. JAMA 2014, 311, 1901-1911. [CrossRef]

18. Jonas, J.B.; Stroux, A.; Velten, I.; Juenemann, A.; Martus, P.; Budde, W.M. Central Corneal Thickness Correlated with Glaucoma Damage and Rate of Progression. Invest. Ophthalmol. Vis. Sci. 2005, 46, 1269-1274. [CrossRef]

19. Dohlman, C.H.; Zhou, C.; Lei, F.; Cade, F.; Regatieri, C.V.; Črnej, A.; Dohlman, J.G.; Shen, L.Q.; Paschalis, E.I. Glaucoma After Corneal Trauma or Surgery-A Rapid, Inflammatory, IOP-Independent Pathway. Cornea 2019, 38, 1589-1594. [CrossRef]

20. Cioffi, G.A. Ischemic model of optic nerve injury. Trans. Am. Ophthalmol. Soc. 2005, 103, 592-613. [CrossRef]

21. Chen, H.; Cho, K.-S.; Vu, T.H.K.; Shen, C.-H.; Kaur, M.; Chen, G.; Mathew, R.; McHam, M.L.; Fazelat, A.; Lashkari, K.; et al. Commensal Microflora-Induced T Cell Responses Mediate Progressive Neurodegeneration in Glaucoma. Nat. Commun. 2018, 9, 3209. [CrossRef] [PubMed]

22. Yang, X.-J.; Ge, J.; Zhuo, Y.-H. Role of Mitochondria in the Pathogenesis and Treatment of Glaucoma. Chin. Med. J. 2013, 126, 4358-4365. [CrossRef] [PubMed]

23. Calkins, D.J.; Pekny, M.; Cooper, M.L.; Benowitz, L.; Lasker/IRRF Initiative on Astrocytes and Glaucomatous Neurodegeneration Participants. The Challenge of Regenerative Therapies for the Optic Nerve in Glaucoma. Exp. Eye Res. 2017, 157, 28-33. [CrossRef] [PubMed] 
24. Walland, M.J.; Carassa, R.G.; Goldberg, I.; Grehn, F.; Heuer, D.K.; Khaw, P.T.; Thomas, R.; Parikh, R. Failure of Medical Therapy despite Normal Intraocular Pressure. Clin. Experiment. Ophthalmol. 2006, 34, 827-836. [CrossRef]

25. Kaden, T.R.; Li, W. Autophagy, mitochondrial dynamics and retinal diseases. Asia Pac. J. Ophthalmol. 2013, 2. [CrossRef]

26. Osborne, N.N.; Núñez-Álvarez, C.; Del Olmo-Aguado, S.; Merrayo-Lloves, J. Visual Light Effects on Mitochondria: The Potential Implications in Relation to Glaucoma. Mitochondrion 2017, 36, 29-35. [CrossRef]

27. Barron, M.J.; Griffiths, P.; Turnbull, D.M.; Bates, D.; Nichols, P. The Distributions of Mitochondria and Sodium Channels Reflect the Specific Energy Requirements and Conduction Properties of the Human Optic Nerve Head. Br. J. Ophthalmol. 2004, 88, 286-290. [CrossRef]

28. Agostinone, J.; Di Polo, A. Retinal Ganglion Cell Dendrite Pathology and Synapse Loss: Implications for Glaucoma. Prog. Brain Res. 2015, 220, 199-216. [CrossRef]

29. Núñez-Álvarez, C.; Osborne, N.N. Blue Light Exacerbates and Red Light Counteracts Negative Insults to Retinal Ganglion Cells in Situ and R28 Cells in Vitro. Neurochem. Int. 2019, 125, 187-196. [CrossRef]

30. Zhao, T.; Li, Y.; Weng, C.; Yin, Z. The Changes of Potassium Currents in RCS Rat Müller Cell during Retinal Degeneration. Brain Res. 2012, 1427, 78-87. [CrossRef]

31. Fischer, R.A.; Roux, A.L.; Wareham, L.K.; Sappington, R.M. Pressure-Dependent Modulation of Inward-Rectifying K+ Channels: Implications for Cation Homeostasis and K+ Dynamics in Glaucoma. Am. J. Physiol. Cell Physiol. 2019, 317, C375-C389. [CrossRef]

32. Pang, J.-J.; Frankfort, B.J.; Gross, R.L.; Wu, S.M. Elevated Intraocular Pressure Decreases Response Sensitivity of Inner Retinal Neurons in Experimental Glaucoma Mice. Proc. Natl. Acad. Sci. USA 2015, 112, 2593-2598. [CrossRef]

33. Risner, M.L.; Pasini, S.; Cooper, M.L.; Lambert, W.S.; Calkins, D.J. Axogenic Mechanism Enhances Retinal Ganglion Cell Excitability during Early Progression in Glaucoma. Proc. Natl. Acad. Sci. USA 2018, 115, E2393-E2402. [CrossRef]

34. Luo, N.; Conwell, M.D.; Chen, X.; Kettenhofen, C.I.; Westlake, C.J.; Cantor, L.B.; Wells, C.D.; Weinreb, R.N.; Corson, T.W.; Spandau, D.F.; et al. Primary Cilia Signaling Mediates Intraocular Pressure Sensation. Proc. Natl. Acad. Sci. USA 2014, 111, 12871-12876. [CrossRef]

35. Patel, P.D.; Chen, Y.-L.; Kasetti, R.B.; Maddineni, P.; Mayhew, W.; Millar, J.C.; Ellis, D.Z.; Sonkusare, S.K.; Zode, G.S. Impaired TRPV4-ENOS Signaling in Trabecular Meshwork Elevates Intraocular Pressure in Glaucoma. Proc. Natl. Acad. Sci. USA 2021, 118. [CrossRef]

36. Ryskamp, D.A.; Frye, A.M.; Phuong, T.T.T.; Yarishkin, O.; Jo, A.O.; Xu, Y.; Lakk, M.; Iuso, A.; Redmon, S.N.; Ambati, B.; et al. TRPV4 Regulates Calcium Homeostasis, Cytoskeletal Remodeling, Conventional Outflow and Intraocular Pressure in the Mammalian Eye. Sci. Rep. 2016, 6, 30583. [CrossRef]

37. Thomas, C.N.; Berry, M.; Logan, A.; Blanch, R.J.; Ahmed, Z. Caspases in Retinal Ganglion Cell Death and Axon Regeneration. Cell Death Discov. 2017, 3, 17032. [CrossRef]

38. Rosso, M.P.D.O.; Buchaim, D.V.; Kawano, N.; Furlanette, G.; Pomini, K.T.; Buchaim, R.L. Photobiomodulation Therapy (PBMT) in Peripheral Nerve Regeneration: A Systematic Review. Bioengineering 2018, 5, 44. [CrossRef]

39. Zhang, J.; Wang, X.; Vikash, V.; Ye, Q.; Wu, D.; Liu, Y.; Dong, W. ROS and ROS-Mediated Cellular Signaling. Oxid. Med. Cell. Longev. 2016, 2016, e4350965. [CrossRef]

40. Albarracin, R.; Natoli, R.; Rutar, M.; Valter, K.; Provis, J. 670 Nm Light Mitigates Oxygen-Induced Degeneration in C57BL/6J Mouse Retina. BMC Neurosci. 2013, 14, 125. [CrossRef]

41. Begum, R.; Powner, M.B.; Hudson, N.; Hogg, C.; Jeffery, G. Treatment with 670 Nm Light up Regulates Cytochrome C Oxidase Expression and Reduces Inflammation in an Age-Related Macular Degeneration Model. PLoS ONE 2013, 8, e57828. [CrossRef] [PubMed]

42. Osborne, N.N.; Núñez-Álvarez, C.; Joglar, B.; del Olmo-Aguado, S. Glaucoma: Focus on Mitochondria in Relation to Pathogenesis and Neuroprotection. Eur. J. Pharmacol. 2016, 787, 127-133. [CrossRef] [PubMed]

43. Albarracin, R.; Eells, J.; Valter, K. Photobiomodulation Protects the Retina from Light-Induced Photoreceptor Degeneration. Invest. Ophthalmol. Vis. Sci. 2011, 52, 3582-3592. [CrossRef] [PubMed]

44. Albarracin, R.; Valter, K. 670 Nm Red Light Preconditioning Supports Müller Cell Function: Evidence from the White LightInduced Damage Model in the Rat Retina. Photochem. Photobiol. 2012, 88, 1418-1427. [CrossRef] [PubMed]

45. Fitzgerald, M.; Hodgetts, S.; Van Den Heuvel, C.; Natoli, R.; Hart, N.S.; Valter, K.; Harvey, A.R.; Vink, R.; Provis, J.; Dunlop, S.A. Red/near-Infrared Irradiation Therapy for Treatment of Central Nervous System Injuries and Disorders. Rev. Neurosci. 2013, 24, 205-226. [CrossRef] [PubMed]

46. Kokkinopoulos, I.; Colman, A.; Hogg, C.; Heckenlively, J.; Jeffery, G. Age-Related Retinal Inflammation Is Reduced by 670 Nm Light via Increased Mitochondrial Membrane Potential. Neurobiol. Aging 2013, 34, 602-609. [CrossRef]

47. Lu, Y.-Z.; Natoli, R.; Madigan, M.; Fernando, N.; Saxena, K.; Aggio-Bruce, R.; Jiao, H.; Provis, J.; Valter, K. Photobiomodulation with 670 Nm Light Ameliorates Müller Cell-Mediated Activation of Microglia and Macrophages in Retinal Degeneration. Exp. Eye Res. 2017, 165, 78-89. [CrossRef]

48. Lu, Y.-Z.; Fernando, N.; Natoli, R.; Madigan, M.; Valter, K. 670 nm Light Treatment Following Retinal Injury Modulates Müller Cell Gliosis: Evidence from in Vivo and in Vitro Stress Models. Exp. Eye Res. 2018, 169, 1-12. [CrossRef]

49. Meng, C.; Xia, Q.; Wu, H.; Huang, H.; Liu, H.; Li, Y.; Zhang, F.; Song, W. Photobiomodulation with 630-Nm LED Radiation Inhibits the Proliferation of Human Synoviocyte MH7A Cells Possibly via TRPV4/PI3K/AKT/MTOR Signaling Pathway. Lasers Med. Sci. 2020, 35, 1927-1936. [CrossRef] 
50. Jimenez-Puerta, G.J.; Marchal, J.A.; López-Ruiz, E.; Gálvez-Martín, P. Role of Mesenchymal Stromal Cells as Therapeutic Agents: Potential Mechanisms of Action and Implications in Their Clinical Use. J. Clin. Med. 2020, 9, 445. [CrossRef]

51. Yazdani, S.O.; Golestaneh, A.F.; Shafiee, A.; Hafizi, M.; Omrani, H.-A.G.; Soleimani, M. Effects of Low Level Laser Therapy on Proliferation and Neurotrophic Factor Gene Expression of Human Schwann Cells in Vitro. J. Photochem. Photobiol. B 2012, 107, 9-13. [CrossRef]

52. Kim, H.B.; Baik, K.Y.; Seonwoo, H.; Jang, K.-J.; Lee, M.C.; Choung, P.-H.; Chung, J.H. Effects of Pulsing of Light on the Dentinogenesis of Dental Pulp Stem Cells in Vitro. Sci. Rep. 2018, 8, 2057. [CrossRef]

53. Wang, Y.; Huang, Y.-Y.; Wang, Y.; Lyu, P.; Hamblin, M.R. Red (660 Nm) or near-Infrared (810 Nm) Photobiomodulation Stimulates, While Blue (415 Nm), Green (540 Nm) Light Inhibits Proliferation in Human Adipose-Derived Stem Cells. Sci. Rep. $2017,7,7781$. [CrossRef]

54. Chen, H.; Wu, H.; Yin, H.; Wang, J.; Dong, H.; Chen, Q.; Li, Y. Effect of Photobiomodulation on Neural Differentiation of Human Umbilical Cord Mesenchymal Stem Cells. Lasers Med. Sci. 2019, 34, 667-675. [CrossRef]

55. Wang, M.; Xu, Z.; Liu, Q.; Sun, W.; Jiang, B.; Yang, K.; Li, J.; Gong, Y.; Liu, Q.; Liu, D.; et al. Nongenetic Optical Modulation of Neural Stem Cell Proliferation and Neuronal/Glial Differentiation. Biomaterials 2019, 225, 119539. [CrossRef]

56. Bernstein, S.L.; Guo, Y.; Kerr, C.; Fawcett, R.J.; Stern, J.H.; Temple, S.; Mehrabian, Z. The Optic Nerve Lamina Region Is a Neural Progenitor Cell Niche. Proc. Natl. Acad. Sci. USA 2020, 117, 19287-19298. [CrossRef]

57. Nuzzi, R.; Marolo, P.; Nuzzi, A. What Is New in Glaucoma: From Treatment to Biological Perspectives. J. Ophthalmol. 2021, 2021. [CrossRef]

58. Wilmsmeyer, S.; Philippin, H.; Funk, J. Excimer Laser Trabeculotomy: A New, Minimally Invasive Procedure for Patients with Glaucoma. Graefes Arch. Clin. Exp. Ophthalmol. 2006, 244, 670-676. [CrossRef]

59. Sivaprasad, S.; Elagouz, M.; McHugh, D.; Shona, O.; Dorin, G. Micropulsed Diode Laser Therapy: Evolution and Clinical Applications. Surv. Ophthalmol. 2010, 55, 516-530. [CrossRef]

60. Santana-Blank, L.; Rodríguez-Santana, E. Photobiomodulation in Light of Our Biological Clock's Inner Workings. Photomed. Laser Surg. 2018, 36, 119-121. [CrossRef]

61. Santana-Blank, L.; Rodríguez-Santana, E.; Santana-Rodríguez, K.E.; Reyes, H. “Quantum Leap" in Photobiomodulation Therapy Ushers in a New Generation of Light-Based Treatments for Cancer and Other Complex Diseases: Perspective and Mini-Review. Photomed. Laser Surg. 2016, 34, 93-101. [CrossRef] [PubMed]

62. Mansouri, V.; Arjmand, B.; Rezaei Tavirani, M.; Razzaghi, M.; Rostami-Nejad, M.; Hamdieh, M. Evaluation of Efficacy of Low-Level Laser Therapy. J. Lasers Med. Sci. 2020, 11, 369-380. [CrossRef] [PubMed]

63. Eells, J.T.; Wong-Riley, M.T.T.; Whelan, H.T. Red to Near-Infrared Photobiomodulation Treatment of the Visual System in Visual System Disease or Injury. U.S. Patent 7,354,432, 8 April 2008.

64. Clark, E.T.; Scott, D.; Scott, B. Devices and Methods for Non-Invasive Multi-Wavelength Photobiomodulation for Ocular Treatments. U.S. Patent 10596037-B2, 24 March 2020.

65. Wu, Z.; Crabb, D.P.; Chauhan, B.C.; Crowston, J.G.; Medeiros, F.A. Improving the Feasibility of Glaucoma Clinical Trials Using Trend-Based Visual Field Progression Endpoints. Ophthalmol. Glaucoma 2019, 2, 72-77. [CrossRef] [PubMed]

66. Quigley, H.A. Clinical Trials for Glaucoma Neuroprotection Are Not Impossible. Curr. Opin. Ophthalmol. 2012, $23,144-154$. [CrossRef] [PubMed]

67. Lucia, U.; Grisolia, G. Thermal Physics and Glaucoma: From Thermodynamic to Biophysical Considerations to Designing Future Therapies. Appl. Sci. 2020, 10, 7071. [CrossRef]

68. Hamblin, M.R. Photobiomodulation or Low-Level Laser Therapy. J. Biophotonics 2016, 9, 1122-1124. [CrossRef] 